\title{
Pengaruh Lamanya Waktu Penyimpanan Biogas Terhadap Komposisi Biogas
}

\author{
( Wayan Putra Adnyana ${ }^{1)^{\star}}$, Tjok. Gde Tirta Nindhia ${ }^{2)}$, ( Wayan Surata ${ }^{2)}$ \\ ${ }^{1)}$ Program Studi Magister Teknik Mesin, Fakultas Teknik Universitas Udayana \\ Kampus Sudirman Denpasar, Bali 80232 \\ Email: iwayanputra adnyana@yahoo.com \\ 2) Jurusan Teknik Mesin, Fakultas Teknik Universitas Udayana \\ Kampus Bukit Jimbaran, Bali 80362 \\ Email: nindhia@yahoo.com, iwasura@gmail.com
}

doi: https://doi.org/10.24843/METTEK.2020.v06.i01.p09

\begin{abstract}
Abstrak
Biogas merupakan gas yang di hasilkan dari limbah organik yang dapat di perbaharui dan dapat di jadikan bioergi, komposisi yang terkandung dalam biogas yaitu gas hydrogen sulfida $\left(\mathrm{H}_{2} \mathrm{~S}\right)$, gas karbon dioksida $\left(\mathrm{CO}_{2}\right)$, oksigen $\left(\mathrm{O}_{2}\right), \mathrm{H}_{2} \mathrm{O}$ dan gas metana $\left(\mathrm{CH}_{4}\right)$. Lamanya waktu penyimpanan biogas yaitu untuk mengetahui pengaruh komposisi biogas selama penyimpanan. Kapasitas bag yang di gunakan dalam penelitian ini berkapasitas 100 lt biogas disimpan selama 21 hari , komposisinya di uji setiap hari sampai hari ke 7 dan kembali di uji komposisinya di hari ke 21 dengan aliran biogas 3 liter per menit. Perbandingan data dalam penelitian ini biogas di simpan dalam 2 bag, bag 1 tersimpan biogas belum di murnikan, bag ke 2 tersimpan biogas yang belum di murnikan dan di tambahkan kalsium klorida $\left(\mathrm{CaCl}_{2}\right)$ di dalam bag. Hasil dari penelitian ini menunjukkan peningkatan komposisi $\mathrm{CH}_{4}$ sebesar $62 \%$ dengan penambahan $\mathrm{CaCl}_{2}$ dalam bag ke 2 dan menurunnya komposisi $\mathrm{H}_{2} \mathrm{~S}$ dsan $\mathrm{CO}_{2}$ dibandingkan biogas yang tersimpan di bag 1 komposisi $\mathrm{CH}_{4}$ hanya $47 \%$.
\end{abstract}

Kata kunci: Biogas, $\mathrm{CH}_{4}, \mathrm{H}_{2} \mathrm{~S}, \mathrm{CO}_{2}$, kalsium klorida $\left(\mathrm{CaCl}_{2}\right)$, bag biogas

\begin{abstract}
Biogas is a gas produced from organic waste that can be renewed and can be made into bioergy, the composition contained in biogas is hydrogen sulfide gas (H2S), carbon dioxide gas (CO2), oxygen gas (O2), $\mathrm{H} 2 \mathrm{O}$ and methane gas (CH4). The length of time for biogas storage is to determine the effect of biogas composition during storage. The capacity of the bag used in this study with a capacity of 100 liters of biogas is stored for 21 days, the composition is tested every day until the 7th day and the composition is tested again on the 21st day with a biogas flow of 3 liters per minute. Comparison of data in this study biogas stored in 2 bags, bag 1 stored biogas not purified, bag 2 stored biogas that has not been purified and added calcium chloride $(\mathrm{CaCl})$ in the bag. The results of this study showed an increase in the composition of $\mathrm{CH} 4$ by $62 \%$ with the addition of $\mathrm{CaCl} 2$ in bag 2 and a decrease in the composition of $\mathrm{H} 2 \mathrm{~S}$ and $\mathrm{CO} 2$ compared to biogas stored in bag 1 in the composition of CH4 was only $47 \%$.
\end{abstract}

Keywords: Biogas, $\mathrm{CH} 4, \mathrm{H} 2 \mathrm{~S}, \mathrm{CO} 2$, calcium chloride (CaCl2), biogas bag.

Penulis korespondensi,

Email: iwayanputra_adnyana@yahoo.com 


\section{PENDAHULUAN}

Proses penguraian bahan-bahan organik oleh bakteri (mikroorganisme) kondisi kedap udara (anaerobik) dengan menghasilkan gas di sebut dengan biogas. Secara alami bakteri yang mengandung bahan organik terdapat dalam limbah, antara lain sampah organik dan limbah dari kotoran peternakan [1]. Pemanfaatan suatu limbah menjadi proses biogas, adalah energi yang layak digunakan baik secara, teknis, sosial maupun secara ekonomis dapat mengatasi masalah energi di pedesaan [2].

[3] Penelitian meningkatkan komposisi metana pada biogas dari 55,2 \% menjadi 77,9\% dengan peningkatan 22,7 \% dengan sistem absorber di dalamnya terdapat larutan kalsium hidroksida $\mathrm{Ca}(\mathrm{OH}) 2$ sebagai absorben dan peningkatan komposisi metana dari 55,2\% menjadi $89,7 \%$ atau meningkat 34,5 \% sistem absorber dengan campuran kalsium hidroksida $\left(\mathrm{Ca}(\mathrm{OH})_{2}\right)$ dan batu zeolit sebagai absorben.

Dari penelitian yang sudah dilakukan masih banyak ditemukan hasil bervariasi terhadap komposisi biogas, oleh karena itu perlu dilakukan penelitan pengaruh lamanya waktu penyimpan biogas terhadap komposisi biogas.

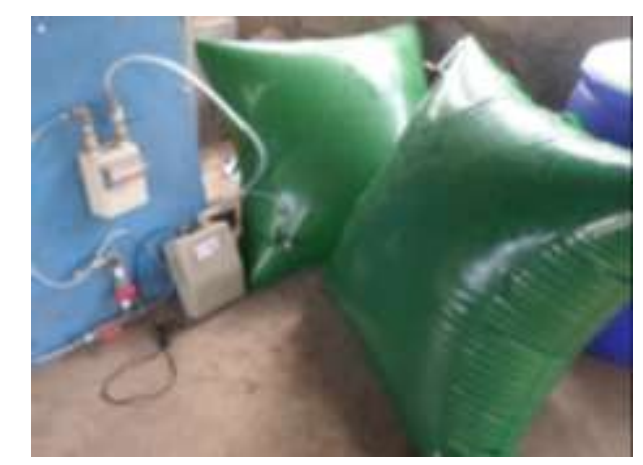

Gambar 1.1 Biogas yang disimpan dalam bag biogas

Berdasarkan latar belakang yang telah dijelaskan sebelumnya, maka dapat dirumuskan suatu permasalahan yang harus diselesaikan yaitu :

1. Bagaimana hasil peningkatan komposisi $\mathrm{CH}_{4}$ pada biogas terhadap lamanya waktu penyimpanan biogas?

2. Bagaimana hasil peningkatan komposisi $\mathrm{CH}_{4}$ komposisi biogas terhadap lamanya waktu penyimpanan biogas dengan penambahan kalsium klorida $\left(\mathrm{CaCl}_{2}\right)$ dalam bag biogas?

Dari banyaknya permasalahan yang ada dan penelitian ini dapat dilaksanakan lebih terarah maka perlu diberikan batasan-batasan permasalahan sebagai berikut :

1. Menggunakan biogas dari kotoran sapi yang di dapat dari simantri 498 Br. Cemadik Pejeng kangin, Kec. Tampaksiring, Gianyar, Bali.

2. Menggunakan 2 bag biogas dengan kapasitas 100 lt.

3. Pengujian komposisi biogas dalam bag di ukur setiap hari di jam yang sama dengan aliran biogas 3 liter/menit. 


\section{METODE PENELITIAN}

Dalam penelitian ini menggunakan 2 bag biogas dengan kapasitas bag yang di gunakan berkapasitas 100 lt biogas disimpan selama 21 hari , komposisinya di uji setiap hari sampai hari ke 7 dan kembali di uji komposisinya di hari ke 21 dengan aliran biogas 3 liter per menit. Perbandingan data dalam penelitian ini biogas di simpan dalam 2 bag, bag 1 tersimpan biogas belum di murnikan, bag ke 2 tersimpan biogas yang belum di murnikan dan di tambahkan kalsium klorida $\left(\mathrm{CaCl}_{2}\right)$ di dalam bag.

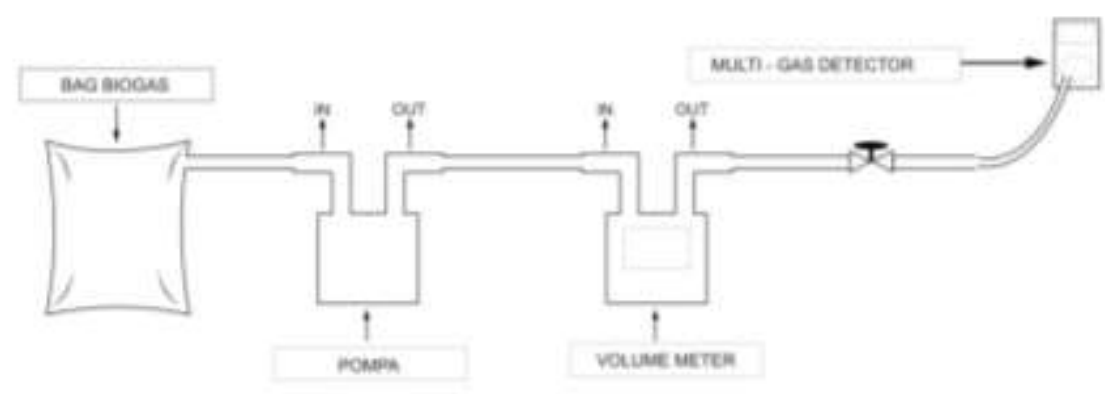

Gambar 2.1 Instalasi pengujian komposisi biogas

Pengujian komposisi biogas mempergunakan peralatan dan bahan sebagai berikut:

1. Bag Biogas untuk menyimpan biogas

2. Pompa Udara digunakan untuk mengaliri biogas di dalam bag biogas

3. Volume meter digunakan untuk mengukur volume biogas dan menentukan aliran biogas 3 liter /menit

4. Timbangan Digital digunakan untuk menimbang komposisi kalsium klorida $\mathrm{CaCl}_{2}$.

5. Instalasi Valve di gunakan untuk mengatur laju aliran biogas saat melakukan pengujian

6. Multi-Gas Detector di gunakan untuk menguji komposisi $\mathrm{CO}_{2}$ (dengan satuan $\%$ volume) dan $\mathrm{H}_{2} \mathrm{~S}$ ( dengan satuan ppm), $\mathrm{CH}_{4}$ yang terdapat dalam biogas

7. Network GC MS Sistem adalah digunakan untuk menguji kandungan komposisi biogas setelah mendapatkan hasil dari pengujian pengaruh lamanya waktu penyimpan biogas terhadap komposisi biogas.

\section{HASIL DAN PEMBAHASAN}

\subsection{Hasil Pengujian Pengaruh Lamanya Waktu Penyimpan Biogas Terhadap Komposisi} Biogas di Bag 1

Dalam bag 1 pengambilan data komposisi biogas dilakukan setiap hari sampai hari ke 7 dan dan di hari ke 21 di jam yang sama yaitu 13:00 dengan aliran biogas 3 liter / menit, analisa penelitian berupa grafik.

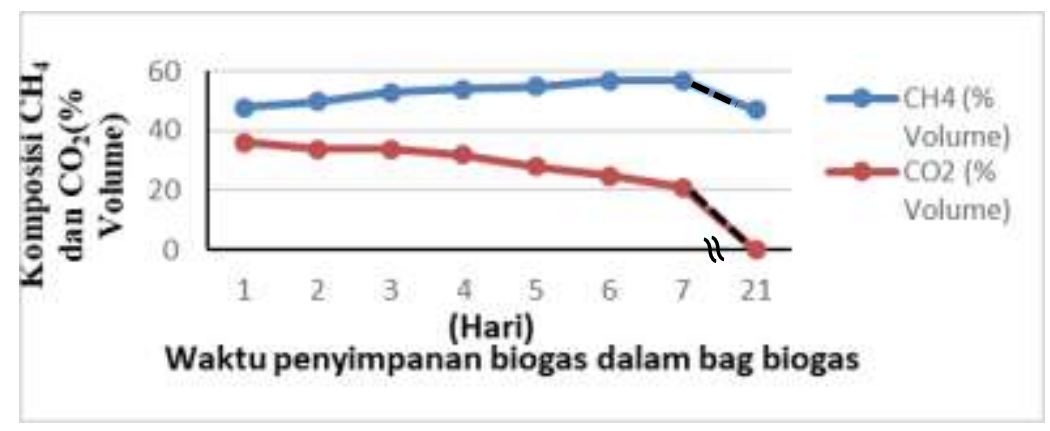




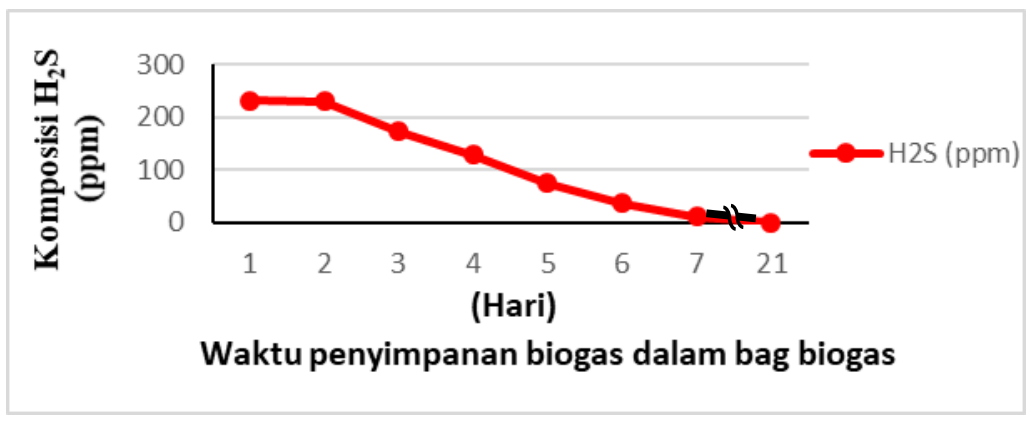

Gambar 3.1 Grafik dari komposisi $\mathrm{CO}_{2}, \mathrm{H}_{2} \mathrm{~S}$ dan $\mathrm{CH}_{4}$ pada biogas di bag 1

Pada gambar 3.1 dijelaskan bahwa biogas yang di simpan dalam bag selama penyimpanan, komposisi $\mathrm{CO}_{2}$ dan $\mathrm{H}_{2} \mathrm{~S}$ mengalami penurunan hingga 0 dan komposisi $\mathrm{CH}_{4}$ peningkatan mulai hari ke 2 sampai hari ke 7 sebanyak $57 \%$ dan menurun lagi di hari ke 21.

\subsection{Hasil Pengujian Pengaruh Lamanya Waktu Penyimpan Biogas Terhadap Komposisi Biogas di Bag 2}

Dalam bag 2 tersimpan biogas dan di dalam bag ditambahkan 26 gr $\mathrm{CaCl}_{2}$, pengambilan data komposisi biogas dilakukan setiap hari sampai hari ke 7 dan di hari ke 21 di jam yang sama yaitu 12:00 dengan aliran biogas 3 liter / menit, analisa penelitian berupa grafik.
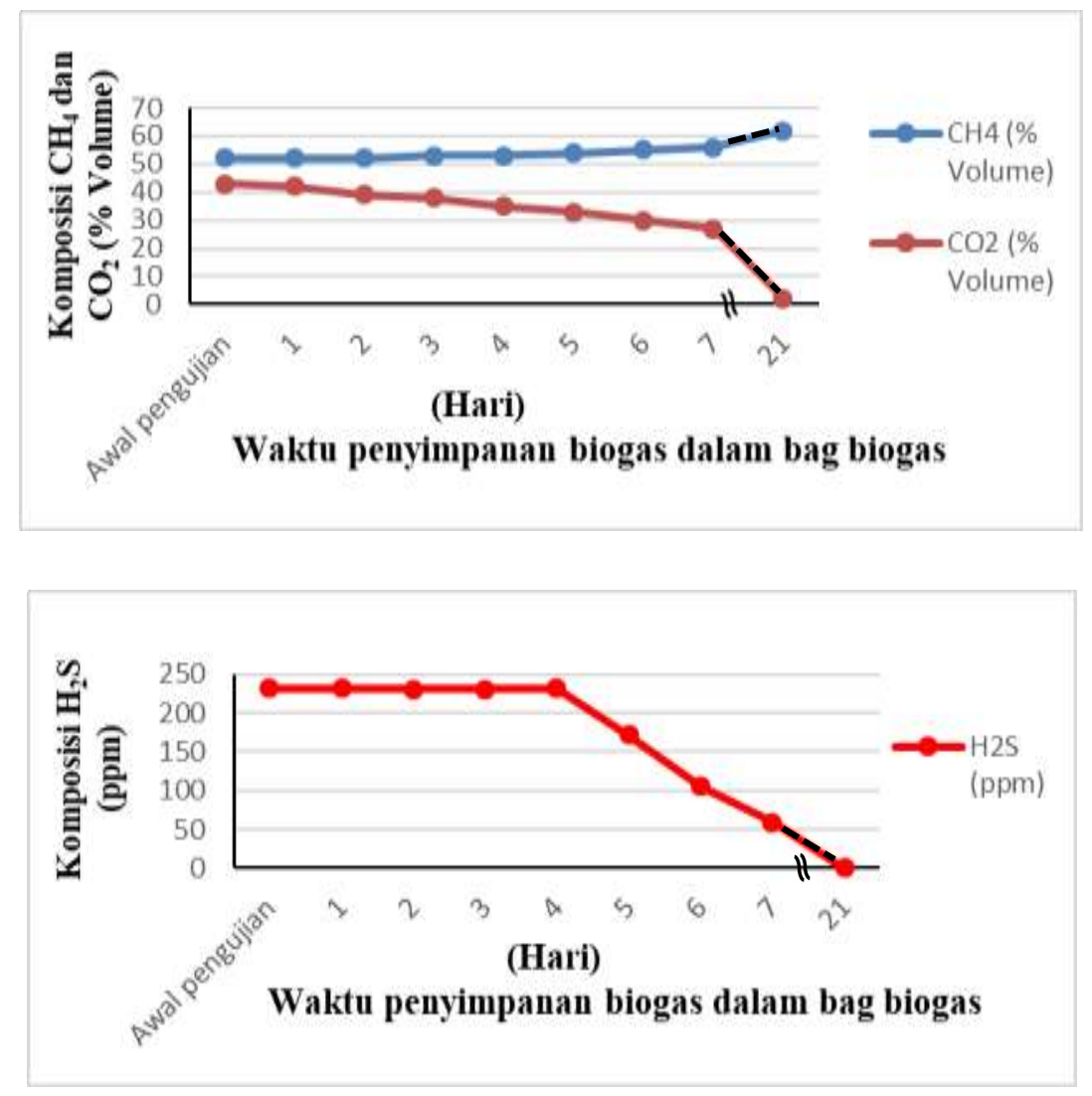

Gambar 3.2.1 Grafik dari komposisi $\mathrm{CO}_{2}, \mathrm{H}_{2} \mathrm{~S}$ dan $\mathrm{CH}_{4}$ pada biogas di bag 2 


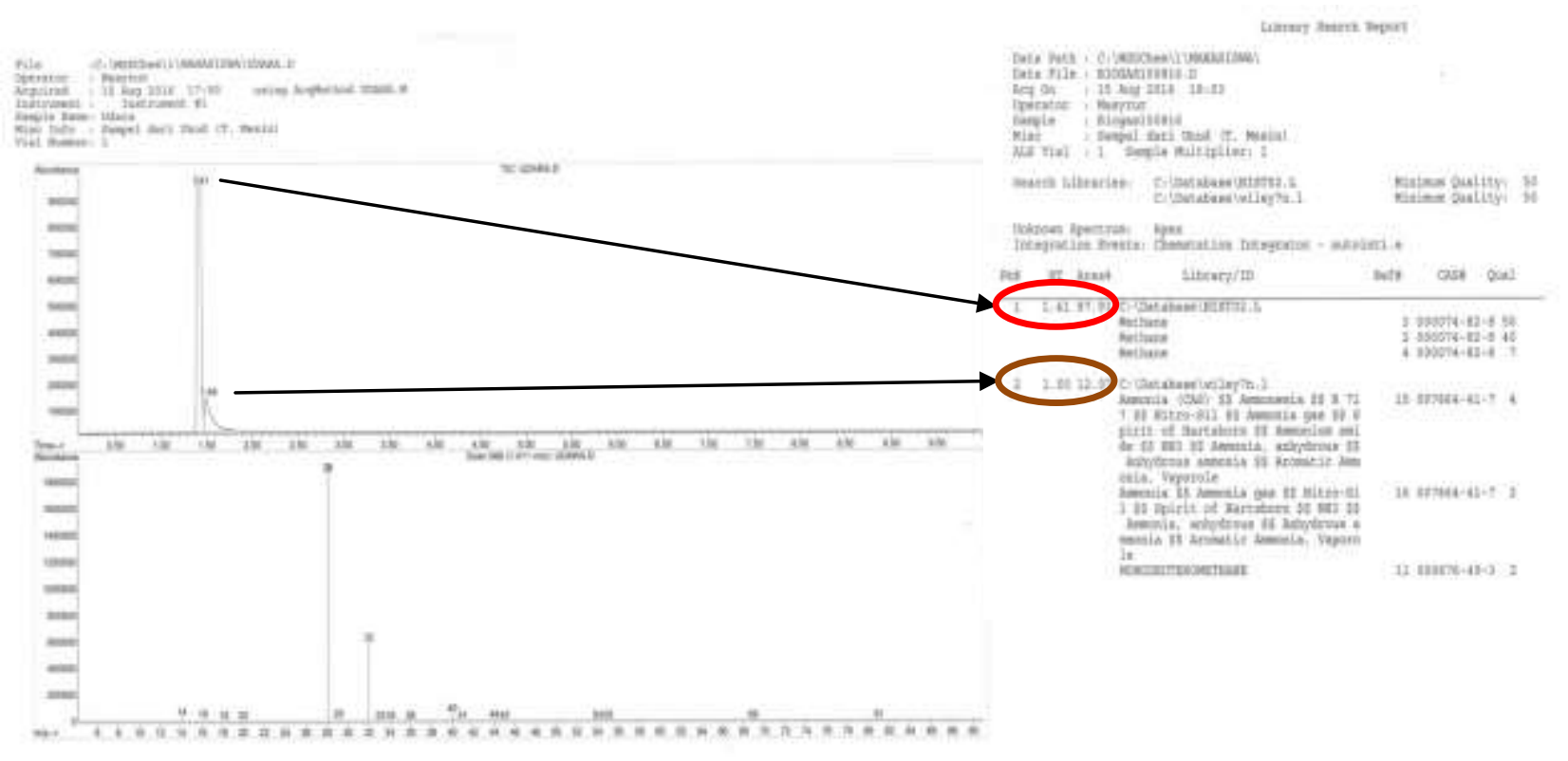

Gambar 3.2.2 komposisi biogas yang di tunjukan dalam grafik 1.50 amonia $\left(\mathrm{NH}_{3}\right)$ dan 1.41metana $\left(\mathrm{CH}_{4}\right)$

Dari gambar 3.2.1 dapat dijelaskan bahwa dengan penambahan kalsium klorida $\left(\mathrm{CaCl}_{2}\right)$ dapat meningkatkan komposisi biogas dari hari 1 sampai hari ke 21 sebanyak $62 \%$ dan menurunnya komposisi $\mathrm{CO}_{2}$ dan $\mathrm{H}_{2} \mathrm{~S}$ hingga 0 dan setelah hasil komposisi biogas dapatkan komposisi biogas kembali diuji dilab forensic hasilnya di tunjukan pada gambar 3.2.2 dan temukannya komposisi amonia $\left(\mathrm{NH}_{3}\right)$ pada biogas. Perubahan fase menjadi amonia $\left(\mathrm{NH}_{3}\right)$ komposisi biogas dijelaskan dengan rumus reaksi sebagai berikut:

Terbentuk hidrogen klorida dan kalsium hidroksida [4] karena hasil reaksi air $\left(\mathrm{H}_{2} \mathrm{O}\right)$ dengan kalsium clorida $\left(\mathrm{CaCl}_{2}\right)$

$$
\mathrm{H}_{2} \mathrm{O}+\mathrm{CaCl}_{2} \longrightarrow \mathrm{Ca}(\mathrm{OH})_{2}+\mathrm{HCl} \text {. }
$$

Reaksi Hidrogen sulfide $\left(\mathrm{H}_{2} \mathrm{~S}\right)$ dengan Kalsium Clorida $(\mathrm{CaCl} 2)$ terbentuk kalsium sulfida dan hidrogen klorida

$$
\mathrm{H}_{2} \mathrm{~S}+\mathrm{CaCl}_{2} \longrightarrow \mathrm{CaS}+\mathrm{HCl}
$$

Reaksi $\mathrm{H}_{2} \mathrm{O}$ dan $\mathrm{CO}_{2}$ dengan kalsium klorida $(\mathrm{CaCl} 2)$ akan terbentuk kalsium karbonat

$$
\begin{aligned}
& \mathrm{CO}_{2}+\mathrm{H}_{2} \mathrm{O} \longrightarrow \mathrm{H}_{2} \mathrm{CO}_{3} \\
& \mathrm{H}_{2} \mathrm{O}+\mathrm{CO}_{2}+\mathrm{CaCl}_{2} \longrightarrow 2 \mathrm{Hcl}+\mathrm{CaCO}_{3}
\end{aligned}
$$

Perubahan fase kalsium klorida $\left(\mathrm{CaCl}_{2}\right)$ dari padat menjadi cair ketika bereaksi dengan komposisi pongotor pada biogas selama waktu penyimpanan. peningkatan komposisi $\mathrm{CH}_{4}$ pada biogas dengan rumus reaksi dari $\mathrm{CH}_{4}$ terrhadap komposisi $\mathrm{H}_{2} \mathrm{O}$ akan terbentuk karbon monoksida $\mathrm{CO}[5]$.

$$
\mathrm{H}_{2} \mathrm{O}+\mathrm{CH}_{4} \longrightarrow \mathrm{CO}+3 \mathrm{H}_{2}
$$

Reaksi antara komposisi $\mathrm{NH}_{3}$ terhadap $\mathrm{CH}_{4}$ akan terbentuk asam sianida (HCN) [6].

$$
\mathrm{NH}_{3}+\mathrm{CH}_{4} \longrightarrow \mathrm{HCN}+3 \mathrm{H}_{2}
$$

Reaksi air $\left(\mathrm{H}_{2} \mathrm{O}\right)$ dengan amonia $\left(\mathrm{NH}_{3}\right)$ akan terbentuk senyawa nitrogen yang menjadi amonium $\left(\mathrm{NH}_{4}\right)$ [7].

$$
\mathrm{H}_{2} \mathrm{O}+\mathrm{NH}_{3} \longrightarrow \mathrm{OH}^{-}+\mathrm{NH}_{4}^{+}
$$

\section{SIMPULAN}

Dari hasil penelitian ini dapat tarik kesimpulan bahwa semakin lama biogas disimpan dengan penambahan kalsium klorida $\left(\mathrm{CaCl}_{2}\right)$ maka semakin tinggi komposisi $\mathrm{CH}_{4}$ biogas dan 
saran dari penelitian ini adalah untuk penelitian lebih lajut dapat dihilangkan komposisi ammonia $\left(\mathrm{NH}_{3}\right)$ pada biogas dan penelitian komposisi biogas di uji secara kontinyu.

\section{UCAPAN TERIMA KASIH}

Mengucapkan terima kasih kepada ketua dari simantri 498 Br. Cemadik Pejeng kangin, Kec. Tampaksiring, Gianyar, Bali sudah menyediakan tempat untuk penelitian ini.

\section{DAFTAR PUSTAKA}

[1] Wahyuni,S.,2011.Menghasilkan Biogas Dari Aneka Limbah, Jakarta, Agro Media Pustaka

[2] Mare,M., 2012, Analisis Penyerapan Gas Karbondioksida $\left(\mathrm{CO}_{2}\right)$ Dengan Larutan $\mathrm{NaOH}$ Terhadap Kualitas Biogas Kotoran Sapi, Dinamika Teknik Mesin, Volume 2 No.1.

[3] Surono,U,B., Macmud,S., 2013, Peningkatan Kualitas Biogas Dengan Metode Absorbsi Dan Pemakaiannya Sebagai Bahan Bakar Mesin Generator Set (Genset), Teknik Mesin Fakultas Teknik, Universitas Janabadra

[4] Prasetyo,H,E., 2012, Pabrik Calcium Chloride Dari Limestone Dengan Proses Netralisasi, UPN Veteran Jatim

[5] Liu, J, A.,2006, Kinetics, catalysis and mechanism of methane steam reforming, Worcester Polytechnic Institute

[6] Grabow, L,C., Studt, F., Albid-Pedersen, F., Pedzold, V., Kleis, J., Bligaard, T., Nørskov, J, K.,2009. Descriptor-based Analysis applied to $\mathrm{HCN}$ synthesis from $\mathrm{NH}_{3}$ and $\mathrm{CH} 4$, Work supported in part by US Department of Energy contract DE-AC02$76 \mathrm{SF} 00515$.

[7] Versteg, P., Rubin, E, S., 2011. A technical and economic assessment of ammoniabased post-combustion $\mathrm{CO}_{2}$ capture at coal-fired power plants, P. Versteeg, E.S. Rubin / International Journal of Greenhouse Gas Control 5 (2011) 1596-1605, Department of Engineering and Public Policy, Carnegie Mellon University, 5000 Forbes Ave., Pittsburgh, PA 15213, USA 